\title{
Questionnaire for Assessing Preschoolers' Organizational Abilities in Their Natural Environments: Development and Establishment of Validity and Reliability
}

\author{
Gila Tubul-Lavy ${ }^{1}$ and Nirit Lifshitz ${ }^{2}$ \\ ${ }^{1}$ Department of Communication Sciences and Disorders, Faculty of Health Profession, Ono Academic College, Kiryat Ono, Israel \\ ${ }^{2}$ Department of Occupational Therapy, Faculty of Health Profession, Ono Academic College, Kiryat Ono, Israel \\ Correspondence should be addressed to Gila Tubul-Lavy; gilatu@gmail.com
}

Received 6 June 2017; Accepted 11 October 2017; Published 7 November 2017

Academic Editor: Elena Nicoladis

Copyright (C) 2017 Gila Tubul-Lavy and Nirit Lifshitz. This is an open access article distributed under the Creative Commons Attribution License, which permits unrestricted use, distribution, and reproduction in any medium, provided the original work is properly cited.

\begin{abstract}
Despite the consensus in the literature regarding the importance of organizational abilities in performing daily tasks, currently there is no assessment that focuses exclusively on such abilities among young children. The study aims to develop a Questionnaire for Assessing Preschoolers' Organizational Abilities (QAPOA), Parents' and Teachers' versions, and to examine their reliability and validity. QAPOA was distributed to preschool teachers and parents of 215 typically developing 4-5.6-year-old children. The teachers' and parents' versions demonstrated good internal consistency. Factor analysis performed to examine the tool's content validity yielded two factors: motor-based and language-based OA. Furthermore, both versions of the questionnaire demonstrated significant differences between OA among boys and girls. Concurrent validity was demonstrated between the QAPOA total scores and the equivalent subscale of the BRIEF-P. Given these findings, different cut-off scores were established for identifying boys and girls with either motor-based and/or language-based OA. The results indicate that both the teachers' and parents' versions of the QAPOA are reliable and valid measures of children's organizational abilities. The questionnaires can assess and identify risk for organizational disabilities as early as preschool age. Thus, it can contribute to the planning of appropriate intervention programs and the prevention of difficulties in the future.
\end{abstract}

\section{Introduction}

Organization is the ability to plan and execute an activity effectively across time and space [1-6].

Children require organizational abilities to participate in age-appropriate daily occupations [7-10]. For example, so as not to disrupt the progression of activities performed at home and in school, they must ensure that the necessary objects are readily accessible, do not become dispersed, or get lost. Spatial organization (school, playground, home) enables children to orient themselves and perform activities independently in familiar environments. Activities of daily living (such as brushing teeth, dressing, eating) should be temporally organized so that the child can meet his/her schedule demands (getting to school/friends/after-school activities) in a timely fashion. Organization of speech is also necessary to communicate one's experiences in the proper sequence so that they can be understood by the listener. Environmental demands for performing school tasks are easier to manage for children with efficient organizational ability [2, 11-14]. The relationship between organizational ability and client factors such as perceptual, motor, cognitive, and language abilities is articulated in both the cognitive and neurodevelopmental frames of reference. Fried [15] emphasizes that organizational ability functions as a "conductor," orchestrating the client functions mentioned above. She presented a cognitive approach that ascribes organization as an executive function $[16,17]$. Executive functioning (EF) refers to higher level cognitive functions, such as formulating and 
executing goals, planning, organization, inhibitory control, working memory, metacognition, and directing brain activity between the cognitive and emotional processing systems [1823].

The neurodevelopmental approach describes the concept of organization according to the sensory integration (SI) framework [1]. SI is a neurological process that organizes sensory input from all sensory channels from within the body and the environment to enable effective functioning. Ayres introduced the concept of praxis, defined as a basic organizational process that incorporates motor ideation, planning, and execution of a purposeful action. Accordingly, praxis refers to the process through which people formulate an idea (what to do) and organize it (how to do it) through a timed sequence of activities, depending on their current spatial context, enabling them to participate in meaningful occupational activities [24]

Organization abilities have been demonstrated in studies of 3-4-year-old children $[15,25]$ Although executive functions in general and organization in particular evolve at a rapid pace during the preschool years [20], there are few reports of standardized assessment tools for preschoolers focusing on organization [19]. Moreover, despite the fact that the young child's everyday environments, both at home and at preschool, are important venues for observing routine manifestations of executive functions in general [8] and organizational abilities in particular, standardized and ecological assessments for young children are scarce [26-28]. A few standardized assessments, such as the Goralnik [29], the Shatil test [30], and the Kaufman Assessment Battery for Children [31], have been developed but they do not assess the child in his/her natural environment. In addition, the Israeli Ministry of Education has published "Mabatim," a tool for use with 3-5-year-old preschoolers to assist teachers in observing and tracking children's preschool performance $[32,33]$, but it relates only to their functioning within the educational environment and has not yet been validated. Other standardized, ecological tools for preschoolers include the Brief-P Inventory of Executive Function for Preschoolers $[34,35]$ and the Performance Skills Questionnaire (PSQ) [36]. These assessments focus on EF in young children, but only partially relate to organizational abilities. Thus, the QAPOA was developed to meet the need for an ecological standardized assessment focusing on organizational abilities among preschoolers and includes both a parents' and teachers' version. This tool enables educators and parents of preschoolers to identify children with rudimentary risk for organizational disabilities at an early age and refer them for further appropriate intervention. The purpose of this study was to establish the validity and reliability of both versions of the QAPOA.

\section{Methods}

2.1. Participants. The study examined a convenience sample of 215 typically developing healthy children ranging from 61 and 68 months $(\mathrm{M}=67.21, \mathrm{SD}=6.08)$, including 118 girls [55\%] and 97 boys [45\%] attending mainstream educational system preschools, as reported by their parents. All were Hebrew speakers. Exclusion criteria included children diagnosed with ADHD, neurodevelopmental disorders, and developmental delays.

\subsection{Instruments}

(1) Demographic Questionnaire for the Preschoolers, which includes items relating to the children and their familial, developmental, and medical background.

(2) The Questionnaire for Assessing Preschoolers' Organizational Abilities (QAPOA, Parents' version (QAPOA-P) and Teachers' version (QAPOA-T)) [37]: these questionnaires are designed to gather information about the child's organizational abilities in his/her everyday environments, home and preschool. Both versions of the QAPOA contain 48 items, 44 of which were accepted through an expert validation process. The other four items, relate to the parent's or teacher's general impression of the child's organizational ability in each occupational area (play, activities of daily living, school, and social interaction), for example, "What is your general impression of the child's organizational abilities at school." The tool is scored on a 5-point Likert scale (1 = "never," 2 = "rarely," 3 = "sometimes," 4 = "usually," 5 = "always"). The total score comprises the sum of scores of the specific items relating to organizational abilities (ranges from 48 to 240). Before completing the questionnaire the respondents are asked to rate their general impression of the child's organizational abilities according to the above scale, presented at the beginning of the questionnaire.

(3) Behavior Rating Inventory of Executive Function, Preschool version (BRIEF-P) [34]: the BRIEF-P is a reliable and valid questionnaire for parents and teachers of preschool-aged children that enable professionals to assess (EF) behaviors in everyday contexts (home and preschool). This questionnaire is designed for children ages 2:0-5:11. It is a 63-item measure with five related but nonoverlapping EF domains: Inhibit, Shift, Emotional Control, Working Memory, and Plan/Organize. It takes 10-15 minutes to complete and is scored on a 3 -point scale $(1=$ "never," $2=$ "sometimes," 3 = "often"). Raw scores are converted to $T$-scores $(\mathrm{M}=50, \mathrm{SD}=10)$, and the cut-off score is 65 (1.5 SD). Studies have demonstrated good internal consistency, temporal stability, and concurrent validity [25].

\subsection{Procedure}

2.3.1. Development of the QAPOA and Examination of Content Validity. Initially, 45 statements were selected for the questionnaire based on the cognitive $[5,15,17]$ and neurodevelopmental [1] theoretical models. The face validity of the 
tool was examined by six pediatric clinicians ( 3 occupational therapists [OTs] and 3 speech-language therapists [SLTs]) with a minimum of 10 years' experience working with preschoolers who were asked whether the statements did (yes) or did not (no) represent the organizational abilities of preschoolers. In accordance with their recommendations, ten items were added.

Next, the content validity of the revised 55-statement item pool was examined through the use of feedback questionnaires sent to 15 expert professionals (preschool teachers, OTs, and SLTs), with over 10 years of experience working with preschoolers. They were asked to rate each item as suitable, somewhat suitable, or very suitable in representing the organizational abilities of preschoolers. Ten questionnaires were completed by four OTs, four SLTs, and two preschool teachers. The maximum total score for each statement was 30 ( 3 points $* 10$ questionnaires, per statement). Only the 44 statements that received 18 or more points (60\% of maximum score) were retained [7]. Examples of statements in the area of play include "selects preferred games at home" and in the area of social interactions "relates and responds appropriately to what others say." In addition, four statements relating to the parent's or teacher's overall impression of the child's organizational ability in the four occupational areas (i.e., play, activities of daily living, preschool, and social interaction) were included, resulting in a total of 48 statements.

Following approval of the Chief Scientist of the Ministry of Education the questionnaires were distributed to the preschool teachers and parents of the participants to initiate the validation process for both versions of the QAPOA $(\mathrm{P} / \mathrm{T})$.

\section{Results}

3.1. Internal Consistency Reliability. The internal consistency (ICC) of both versions of the QAPOA (P/T) was found to be very high ( $\alpha=0.97$ and 0.94 , resp.).

3.2. Construct Validity. Factor analysis yielded two factors for each version of the questionnaire, namely, motor-based organizational abilities and language-based organization abilities (Tables 1 and 2)

As can be seen from these tables a high ICC was found between the items in each factor. Notably, according to both the teacher's and parents' reports, a significant difference was found between boys' and girls' scores $(t=-4.11, p<0.001$; $t=-2.69, p<0.01$, resp.) (Tables 1 and 2 ).

3.3. Convergent Validity. Pearson's correlational analyses revealed significant correlations between the preschool teachers' total organization score on the QAPOA and the $t$-score on the BRIEF-P Planning and Organization scale, kindergarten teacher's version $(r=0.46 ; p<0.001)$, and between the QAPOA total organization scores and the teacher's overall impression of the children's organizational abilities $(r=0.73$. $p<0.001)$. Similar findings were found for the parents' scores on these scales (i.e., parent's total QAPOA organization score and the BRIEF-P $t$-score, $r=-0.41, p<0.001$; QAPOA$\mathrm{P}$ total score, and parents' overall impression of children's organization, $r=0.57, p<0.001$ ).

3.4. Questionnaire Cut-Off Scores Indicating Difficulty in Organization. The QAPOA cut-off scores were found to be different for boys and girls, both with respect to total scores and the motor and language subscale scores. Total and subscale scores at or under the 16th percentile were identified as cut-off scores, indicating a risk for difficulties in organization. Thus, the identified total organization cutoff score for boys on the QAPOA-T was 173 and 185 on the QAPOA-P, and for girls it was 192 (QAPOA-T) and 196 (QAPOA-P). The same held true for cut-off scores for each subscale, in accordance with the findings of the factor analysis reported in Tables 1 and 2 .

Specifically, the total cut-off score for boys on the QAPOA-T motor organization subscale was found to be 68, and it was 71 on the QPAOA-P, representing scores at or under the 16th percentile. For girls the total cut-off score signifying risk for organizational difficulties in the QAPOA$\mathrm{T}$ was 76 , and on the QAPOA-P it was 77. On the languagerelated organization subscale, the following cut-off scores were identified: for boys on the QAPOA-T $=90$ and on the QAPOA-P $=94$; for girls on the QAPOA-T $=99$ and on the QAPOA-P $=100$.

\section{Discussion and Summary}

The aim of the current research was to describe the development and examine the psychometric properties of the QAPOA, a practical, user-friendly tool for evaluating children's organizational abilities in ordinary life situations at kindergarten and at home. The statistical analyses found the QAPOA to be a valid and reliable tool.

4.1. Internal Consistency. Internal consistency refers to the extent to which the individual items in an instrument measure the same construct. The statistic generated is a correlation coefficient ranging from 0 and +1.00 , and a correlation of 0.80 is considered to demonstrate adequate reliability [38].

The item-selection procedure for the QAPOA was based on cognitive and neurodevelopmental theoretical models, as well as on the clinical experience of experts in preschool education and related therapy services (OT, SLP). The meticulous item-selection process described above testifies as to its content validity, supported by the high Cronbach's coefficient values found for both versions of the tool (QAPOA-P, $\alpha=$ 0.94; QAPOA-T, $\alpha=0.97$ ).

According to the neurodevelopmental [1] and cognitive $[15,17]$ theoretical approaches upon which the initial item selection was based, organization is conceptualized in terms of its spatial and temporal dimensions. However, during the process of item selection, the need arose to also consider the organizational abilities needed for effective social interaction, as exemplified by items such as "relates to initiatives of peers during free play" or "seeks help when needed from adults or 
TABLE 1: QAPOA-T* factor loading and Cronbach's alpha.

\begin{tabular}{|c|c|c|c|}
\hline Item number & Item & $\begin{array}{c}\text { Factor } 1 \\
\text { Language-based }\end{array}$ & $\begin{array}{c}\text { Factor } 2 \\
\text { Motor-based }\end{array}$ \\
\hline 1 & Selects preferred game in preschool & & 0.50 \\
\hline 2 & Selects preferred game in preschool playground & & 0.48 \\
\hline 3 & $\begin{array}{l}\text { Places game pieces correctly in space (assembles in accordance with a } \\
\text { model) }\end{array}$ & & 0.45 \\
\hline 4 & Uses playground equipment efficiently (i.e., ladders, swings) & & 0.47 \\
\hline 5 & Moves about freely in space without stumbling over obstacles & & 0.67 \\
\hline 6 & $\begin{array}{l}\text { Times body movements appropriately during motor activities (i.e., hand } \\
\text { games, ball games) }\end{array}$ & & 0.62 \\
\hline 7 & Plays board games according to the rules of play & 0.49 & \\
\hline 8 & Initiates stories and/or rules during free play & & 0.53 \\
\hline 9 & $\begin{array}{l}\text { Relates to the initiatives of another child during free play (suggested } \\
\text { activity, change in game) }\end{array}$ & & 0.54 \\
\hline 10 & Follows the sequence of a game & & 0.61 \\
\hline 11 & Conveys ideas intelligibly to other players & 0.68 & \\
\hline 12 & Maintains personal space during group work at the table & & 0.78 \\
\hline 13 & Keeps the workspace neat and clean & & 0.74 \\
\hline 14 & Conducts meaningful conversation with other children during group work & 0.66 & \\
\hline 15 & Cuts effectively & & 0.66 \\
\hline 16 & Uses suitable quantities of glue & & 0.72 \\
\hline 17 & Places drawn or pasted items correctly on the page & & 0.65 \\
\hline 18 & Completes work sheet at a rate comparable to most of his/her classmates & & 0.54 \\
\hline 19 & Arranges items according to sequence (i.e., colors, shapes, numbers) & 0.58 & \\
\hline 20 & Analyzes/synthesizes words into/from phonemes & 0.66 & \\
\hline 21 & $\begin{array}{l}\text { Performs activities that include spatial concepts (i.e., "put the. . . in front } \\
\text { of/outside the...") }\end{array}$ & 0.70 & \\
\hline 22 & Follows instructions in sequence (i.e., "put the... and then pick up the...") & 0.65 & \\
\hline 23 & Conducts self- according to the accepted preschool routine & & 0.63 \\
\hline 24 & Adapts to changes in preschool activities & & 0.54 \\
\hline 25 & Organizes a story sequence using pictures & 0.65 & \\
\hline 26 & Describes a story sequence using pictures & 0.74 & \\
\hline 27 & Relates experiences and topics learned in preschool & 0.72 & \\
\hline 28 & Imitates a sequence of movements (i.e., a dance) & & 0.63 \\
\hline 29 & $\begin{array}{l}\text { Performs daily activities according to the correct sequence (i.e., preparing a } \\
\text { sandwich, eating) }\end{array}$ & & 0.57 \\
\hline 30 & Able to convey personal information (family members, address, age) & 0.50 & \\
\hline 31 & Seeks help from an adult when needed & 0.48 & \\
\hline 32 & Operates devices (i.e., spreads with a knife, unzips pants or lunch bag) & & 0.51 \\
\hline 33 & Independent in toileting & & 0.45 \\
\hline 34 & Maintains personal hygiene (when eating, bathing, dressing) & & 0.60 \\
\hline 35 & $\begin{array}{l}\text { Puts personal belongings in their proper place (i.e., hangs up coat, puts } \\
\text { pictures in drawer) }\end{array}$ & & 0.62 \\
\hline 36 & Focuses on topic of discussion and not associative topics & 0.66 & \\
\hline 37 & Shares a personal experience in an organized understandable manner & 0.78 & \\
\hline 38 & Formulates questions correctly & 0.80 & \\
\hline 39 & Relates and responds appropriately to what others say & 0.73 & \\
\hline 40 & $\begin{array}{l}\text { Seeks help from an adult or a child when needed using gestures, words, or } \\
\text { sentences }\end{array}$ & 0.66 & \\
\hline 41 & $\begin{array}{l}\text { Uses properly constructed sentences for conveying experiences/ideas } \\
\text { (vocabulary, grammar and sentence structure) }\end{array}$ & 0.80 & \\
\hline 42 & Pronounces words clearly and intelligibly to the listener & 0.78 & \\
\hline 43 & $\begin{array}{l}\text { Speech is accompanied by appropriate gestures, intonation, and facial } \\
\text { expressions }\end{array}$ & 0.61 & \\
\hline \multirow[t]{2}{*}{44} & Adapts to a variety of social situations & 0.51 & \\
\hline & Cronbach's $\alpha$ & 0.96 & 0.93 \\
\hline
\end{tabular}

\footnotetext{
* QAPOA-T: Questionnaire for Assessing Preschoolers' Organizational Abilities, Teachers' version.
} 
TABLE 2: QAPOA-P* factor loading and Cronbach's alpha.

\begin{tabular}{|c|c|c|c|}
\hline Item number & Item & $\begin{array}{c}\text { Factor } 1 \\
\text { Language-based }\end{array}$ & $\begin{array}{c}\text { Factor } 2 \\
\text { Motor-based }\end{array}$ \\
\hline 1 & Selects preferred game at home & & 0.36 \\
\hline 2 & Selects preferred game and/or equipment in the playground & & 0.33 \\
\hline 3 & $\begin{array}{l}\text { Places game pieces correctly in space (assembles in accordance with a } \\
\text { model) }\end{array}$ & & \\
\hline 4 & Uses playground equipment efficiently (i.e., ladders, swings) & & 0.50 \\
\hline 5 & Moves about freely in space without stumbling over obstacles & & 0.59 \\
\hline 6 & $\begin{array}{l}\text { Times body movements appropriately during motor activities (i.e., hand } \\
\text { games, ball games) }\end{array}$ & & 0.70 \\
\hline 7 & Plays board games according to the rules & & 0.40 \\
\hline 8 & Initiates stories and/or establishes rules during free play & 0.38 & \\
\hline 9 & Relates to the initiatives of another child during free play & & 0.42 \\
\hline 10 & Follows the sequence of a game & & 0.54 \\
\hline 11 & Conveys ideas intelligibly to other players & 0.64 & \\
\hline 12 & $\begin{array}{l}\text { Selects an appropriate place to perform activities (drawing, coloring, } \\
\text { completing work sheets) }\end{array}$ & & 0.51 \\
\hline 13 & Keeps the workspace organized and clean & & 0.31 \\
\hline 14 & Conducts a conversation with an adult to get information & 0.63 & \\
\hline 15 & Cuts effectively & & 0.50 \\
\hline 16 & Uses suitable quantities of glue & & 0.51 \\
\hline 17 & Places drawn or pasted items correctly on a page & & 0.55 \\
\hline 18 & Completes work sheet at a reasonable rate & & 0.50 \\
\hline 19 & Arranges items according to sequence (i.e., colors, shapes, numbers) & 0.44 & \\
\hline 20 & Analyzes/synthesizes words into/from phonemes & 0.58 & \\
\hline 21 & $\begin{array}{l}\text { Performs activities that include spatial concepts (i.e., "put the. . . in front } \\
\text { of/outside the...") }\end{array}$ & 0.64 & \\
\hline 22 & $\begin{array}{l}\text { Follows complex instructions in sequence (i.e., "put the... and then pick up } \\
\text { the...") }\end{array}$ & 0.64 & \\
\hline 23 & Conducts self -according to accepted daily home routine & & 0.55 \\
\hline 24 & Adapts to changes in home activities & & 0.56 \\
\hline 25 & Organizes and describes a story sequence using pictures & 0.67 & \\
\hline 26 & Relates experiences and topics learned in preschool & 0.51 & \\
\hline 27 & Imitates a sequence of movements (i.e., a dance) & & 0.38 \\
\hline 28 & Uses newly learned words in their proper context & 0.70 & \\
\hline 29 & $\begin{array}{l}\text { Performs daily activities according to the correct sequence (i.e., gets } \\
\text { dressed, personal hygiene) }\end{array}$ & 0.49 & \\
\hline 30 & Able to convey personal information (family members, address, age) & 0.47 & \\
\hline 31 & Seeks help from an adult when needed & & \\
\hline 32 & $\begin{array}{l}\text { Parent: operates devices such as a knife for spreading, opens lunch bag' or } \\
\text { pants' zippers) }\end{array}$ & & 0.43 \\
\hline 33 & Independent in toileting & & 0.43 \\
\hline 34 & Blows nose and maintains personal hygiene & & 0.55 \\
\hline 35 & Puts personal belongings in their proper place (i.e., organizes toys) & & 0.59 \\
\hline 36 & Focuses on topic of discussion and not associative topics & 0.62 & \\
\hline 37 & Shares a personal experience in an organized understandable manner & 0.72 & \\
\hline 38 & Formulates questions correctly & 0.78 & \\
\hline 39 & Relates and responds appropriately to what others say & 0.66 & \\
\hline 40 & $\begin{array}{l}\text { Seeks help from an adult or a child when needed using gestures, words, or } \\
\text { sentences }\end{array}$ & 0.53 & \\
\hline 41 & $\begin{array}{l}\text { Uses properly constructed, understandable sentences for conveying } \\
\text { experiences/ideas (vocabulary, grammar, and sentence structure) }\end{array}$ & 0.80 & \\
\hline 42 & Pronounces words clearly and intelligibly to the listener & 0.70 & \\
\hline 43 & $\begin{array}{l}\text { Speech is accompanied by appropriate gestures, intonation, and facial } \\
\text { expression }\end{array}$ & 0.59 & \\
\hline \multirow[t]{2}{*}{44} & Adapts to a variety of social situations & & 0.50 \\
\hline & Cronbach's $\alpha$ & 0.94 & 0.79 \\
\hline
\end{tabular}

*QAPOA-P: Questionnaire for Assessing Preschoolers' Organizational Abilities, Parents' version. 
children through gestures, spoken words, or sentences." Thus, we propose the following expanded definition of organizational skills: the ability to set meaningful goals and plan and execute them efficiently and successfully in the appropriate order and sequence, temporally and spatially with objects and people.

4.2. Construct Validity. Construct validity is defined as the extent to which an operationalization measures the concept it is supposed to measure [38, 39]. Factor analysis is one approach used to establish construct validity for the purpose of determining how unobserved or latent factors exert directional influences on participants' responses of observed variables. It helps the researcher identify the number and nature of such latent factors [40].

The QAPOA questionnaire items were categorized according to the major occupations characterizing children's everyday activities: playing, learning, and daily activities of living and social interaction [41]. Therefore, it was hypothesized that factor analysis would group the items into four factors corresponding to these four occupational areas. However, surprisingly, the items clustered into two factors: motor-based organizational skills, reflecting children's motor abilities (what and how to do), and language-based organizational skills, reflecting children's language ability (what and how it is said).

In light of this finding, three different cut-off scores were established to determine whether a child is within the normal range of organizational abilities: one for total organization, for motor-based organization, and for language-based organization.

The disclosure of these two factors enable us to conduct a more in depth, comprehensive assessment process that relates to client factors underlying organizational abilities. For example, "puts personal belongings in their proper place" (QAPOA-P, item 35) represents a motor-based expression of a child's organizational abilities in the natural environment. If the child scores below the cut-off, he/she can be referred for further evaluation by an Occupational Therapist (OT). Likewise, "seeks help from an adult or a child when needed using gestures, words, or sentences" (QAPOA-P, item 40) represents a language-based expression of a child's organizational abilities in his/her natural environment. Children obtaining a score below the cut-off in this area can be referred to a Speech-Language Pathologist (SLP). If a child scores below the cut-off for both motor- and language-based organization, he/she can be referred for both occupational and speech therapy and may need to be referred to other types of professionals.

4.3. Gender Differences. Another way to examine the construct validity of a tool is to examine whether it distinguishes between populations. The QAPOA-P/T was found to distinguish between boys and girls, such that for both versions the cut-off score for boys for total organizational abilities as well as for motor- and language-based organizational abilities was lower than that for girls. The BRIEF-P [34] also has different cut-off points for boys and girls, and there too the cut-off score for boys is lower than for girls. In contrast, no gender differences were found in the My Child's Play Questionnaire [42], a parental questionnaire that examines play abilities among 3-9-year-old children, even within the subscale of executive functioning.

Convergent validity measures the extent to which the underlying constructs of an assessment tool are similar to those measured by established, validated instruments [43]. In the current study, the convergent validity of the QAPOA-P/T was supported by moderate-significant correlations found with questions from the BRIEF-P that assess planning and organization, in both the parents' and kindergarten-teachers' versions. This finding provides evidence that the construct of organization, as examined in both tools, is similar. However, the degree to which the observation of behavior is representative of this construct differs between them. Specifically, the BRIEF-P is comprised of 63 statements, of which only 10 questions refer to organizational abilities. In contrast, the essence of the QAPOA-T/P is to examine organization abilities in a more comprehensive manner, such that all 48 items examine these abilities. For example, while only one item deals with organization abilities during play in BRIEFP, QAPOA specifies 11 of such abilities as preferred game selection, story initiation, and respecting game rules. Likewise, nonitems in BRIEF-P concern organizational abilities during social communication, while QAPOA includes nine items/statements dealing with these abilities, like focusing on the topic of discussion, experience sharing, seeking help, referring to what was said by the other (see Tables 1 and 2 for the all the items). Since several areas in the QAPOA-T/P are not covered by the BRIEF-P, further validation should be considered with other subtests or assessment tools that examine organizational abilities (e.g., 30, 31, 37).

\section{Conclusion}

The findings of the current study support the reliability and validity of preschool teachers' and parents' versions of the QAPOA in assessing organizational abilities among Hebrewspeaking preschoolers. Data on reliability and validity should be taken into account before using QAPOA in other cultures.

As noted above, the process of developing the questionnaire raised the need for a new, more comprehensive definition of the construct of organization that relates to motor- and language-based organization abilities and to establishing cutoff scores according to gender. This questionnaire represents a more focused foundation upon which professionals can base their continued evaluation according to the various body functions.

This process informs us of the need for a more comprehensive top-down model for evaluating children's organizational abilities and should relate to the relevant abilities needed in their natural environment. Further assessment should then include the evaluation of body functions within the various therapeutic domains. Figure 1 illustrates such a model, which provides a structured and comprehensive guide that can serve to streamline the evaluation process 


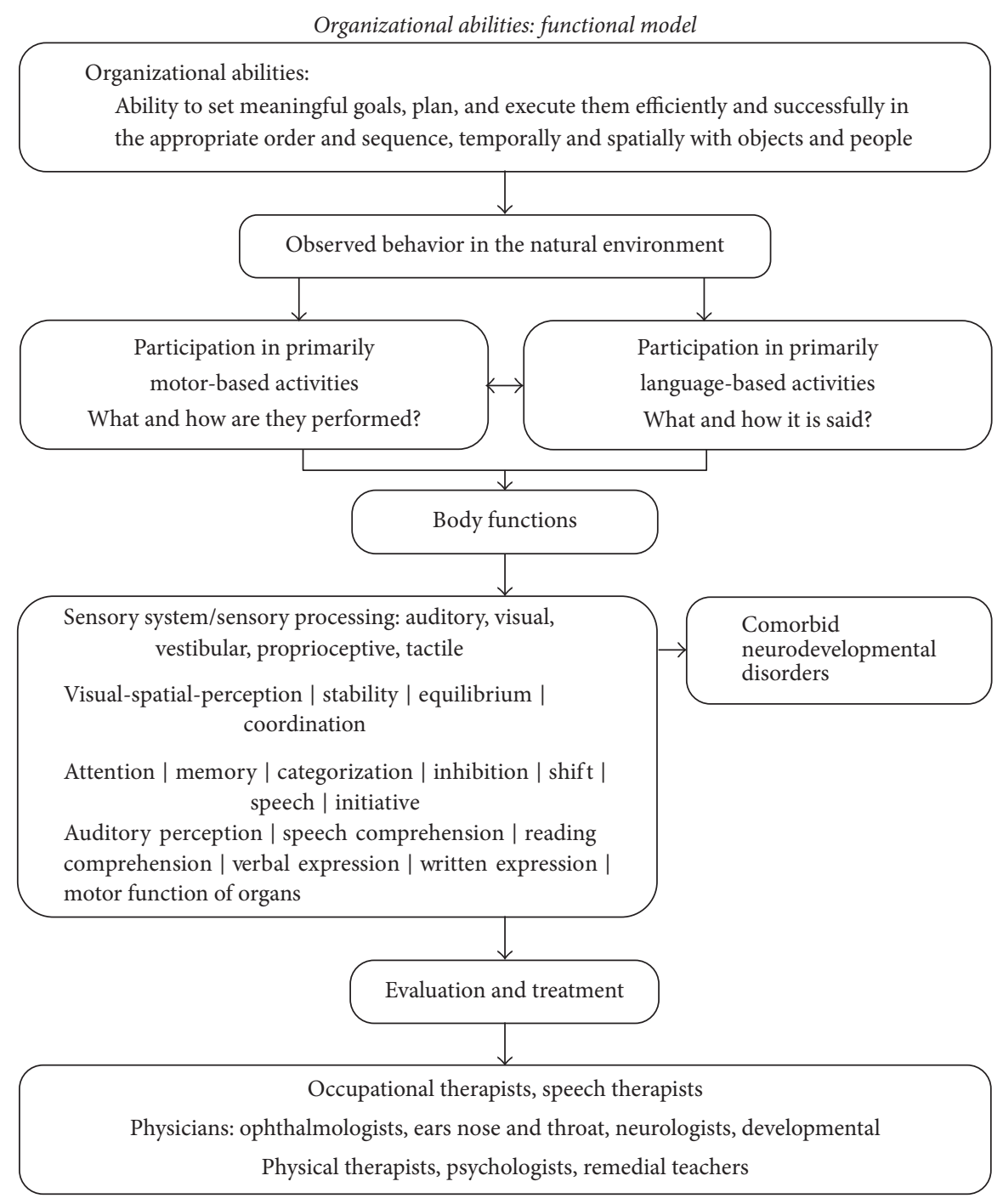

FIGURE 1: Organizational abilities: functional model.

of organizational abilities among children. The use of the approach delineated in this model can enable the creation of a more personalized intervention program for children with organizational disabilities.

\section{Conflicts of Interest}

The authors declare that there are no conflicts of interest regarding the publication of this paper.

\section{Acknowledgments}

The authors are grateful to the parents and teachers of the preschoolers who participated in the study. The authors wish to thank the students in the research seminar courses in the Speech and Language Pathology and Occupational Therapy Departments at Ono Academic College for their assistance in data collection. Finally thanks are due to Professor Noomi Katz, Director of the Research Institute for Health \& Medical
Professions at Ono Academic College, and to Dr. Yossi Frier for their support and counsel through all phases of the present study.

\section{References}

[1] A. J. Ayers, Sensory Integration and Praxis Test, Western Psychological Service, Los Angeles, Calif, USA, 1989.

[2] M. Levine, A Mind at a Time, Simon \& Schuster, New York, NY, USA, 2002

[3] N. Lifshitz, N. Josman, and E. Tirosh, "Validation of the Questionnare for Assessing Students' Organizational Abilities (QASOA)," The Israeli Journal of Occupational Therapy, vol. 22, no. 3, pp. 53-69, 2013.

[4] N. Lifshitz, N. Josman, and E. Tirosh, "Disorganization as related to discoordination and attention deficit," Journal of Child Neurology, vol. 29, no. 1, pp. 66-70, 2014.

[5] C. M. Temple, "Cognitive neuropsychology and its application to children," Journal of Child Psychology and Psychiatry and Allied Disciplines, vol. 38, no. 1, pp. 27-52, 1997. 
[6] S. S. Zentall, G. W. Harper, and M. Stormont-Spurgin, "Children With Hyperactivity and Their Organizational Abilities," Journal of Educational Research, vol. 87, no. 2, pp. 112-117, 1993.

[7] N. Lifshitz and N. Josman, "Development of the Questionnaire for Assessing the Student's Organizational Abilities (QASOA): establishing reliability and validity," Israeli Journal of Occupational Therapy, vol. 15, pp. H5-H29, 2006.

[8] P. Dawson and R. Guare, Executive skills in children and adolescents, The Guildford Press, New York, NY, USA, 2004.

[9] T. Aharon, T. Menachem- Eitan, M. Kalingel-Levi et al., “The Relationship between organizational abilities and sensory processing among preschoolers,' Israeli Journal of Occupational Therapy, vol. 26, no. 1, pp. H28-H43, 2017 (Hebrew).

[10] G. Tubul-Lavy and N. Lifshitz, "Organizational abilities among kindergarten children: comparison between children with developmental delay and typical children," Speech \& Hearing, vol. 35, pp. 57-70, 2016 (Hebrew).

[11] M. Malekpour and S. Aghababaei, "The effect of executive functions training on the rate of executive functions and academic performance of students with learning disability," International Journal of Developmental Disabilities, vol. 59, no. 3, pp. 145-155, 2013.

[12] M. Semrud-Clikeman, "Neuropsychological aspects for evaluating learning disabilities," Journal of Learning Disabilities, vol. 38, no. 6, pp. 563-568, 2005.

[13] S. Rosenblum, T. Aloni, and N. Josman, "Relationships between handwriting performance and organizational abilities among children with and without dysgraphia: a preliminary study," Research in Developmental Disabilities, vol. 31, no. 2, pp. 502509,2010

[14] T. E. Brown, "Executive functions and attention deficit hyperactivity disorder: implications of two conflicting views," International Journal of Disability, Development and Education, vol. 53, no. 1, pp. 35-46, 2006.

[15] R. Fried, "Neuropsychology of Attention-Deficit Hyperactivity Disorder (ADHD)," in Proceedings of the ADHA Worldwide - 1st Joint Meeting, Tel Aviv, Israel, 2013.

[16] N. Josman and S. Rosenblum, "A metacognitive model for children with atypical brain development," in Cognition, Occupation and Participation Across the Life Span, N. Katz, Ed., pp. 223-247, AOTA, Bethesda, Md, USA, 3rd edition, 2011.

[17] J. Toglia, "The multicontext approach to cognitive rehabilitation of executive function," in Proceedings of the Workshop presented at the Research Institute for Health \& Medical Professions, Ono Academic College, Israel, 2011.

[18] P. J. Anderson, "Towards a developmental model of executive function," in Executive Functions and the Frontal Lobes: A Lifespan Perspective, V. Anderson and P. J. Anderson, Eds., pp. 3-22, Psychology Press, New York, NY, USA, 2008.

[19] P. J. Anderson and N. Reidy, "Assessing executive function in preschoolers," Neuropsychology Review, vol. 22, no. 4, pp. 345360, 2012.

[20] K. A. Espy, T. D. Sheffield, S. A. Wiebe, C. A. C. Clark, and M. J. Moehr, "Executive control and dimensions of problem behaviors in preschool children," Journal of Child Psychology and Psychiatry and Allied Disciplines, vol. 52, no. 1, pp. 33-46, 2011.

[21] M. Ylvisaker and T. Feeney, "Executive functions, selfregulation, and learned optimism in paediatric rehabilitation: a review and implications for intervention," Journal of Pediatric Rehabilitation Medicine, vol. 5, no. 2, pp. 51-70, 2002.
[22] R. A. Barkley, "Behavioral inhibition, sustained attention, and executive functions: constructing a unifying theory of ADHD," Psychological Bulletin, vol. 121, no. 1, pp. 65-94, 1997.

[23] P. D. Zelazo, A. Carter, J. S. Reznick, and D. Frye, "Early development of executive function: a problem-solving framework," Review of General Psychology, vol. 1, no. 2, pp. 198-226, 1997.

[24] E. R. Blanche and L. D. Parham, "Praxis and organization of behavior in time and space," in Understanding the Nature of Sensory Integration with Diverse Populations, S. S. Roley, E. I. Blanche, and R. C. Schaaf, Eds., pp. 183-200, Communication Skill Builders, 2001.

[25] A. H. Skogan, J. Egeland, P. Zeiner et al., "Factor structure of the Behavior Rating Inventory of Executive Functions (BRIEFP) at age three years," Child Neuropsychology, vol. 22, no. 4, pp. 472-492, 2016.

[26] P. A. Crist, "Framing ecological validity in occupational therapy practice," The Open Journal of Occupational Therapy, vol. 3, no. 3, pp. 1-8, 2015.

[27] A. Golos and N. Weintraub, "The structured Preschool Participation Observation (SPQ): development and validation," he Israeli Journal of Occupational Therapy, vol. 24, pp. H59-H72, 2015.

[28] M. Badia, M. Begoña Orgaz, M. Gómez-Vela, M. A. Verdugo, A. M. Ullán, and E. Longo, "Do environmental barriers affect the parent-reported quality of life of children and adolescents with cerebral palsy?" Research in Developmental Disabilities, vol. 4950, pp. 312-321, 2016.

[29] E. Goralnik, Language Screening Test for Hebrew-Speaking Preschool Children, Gai Agencies, Netanya, Israel, 1995.

[30] E. Shatil, Shatil Test for the Assessment of at-risk Preschool Children, Ach Publishing, Haifa, Israel, 2002.

[31] D. Loomis, R. Holt, J. C. Kaufman, and A. S. Kaufman, "Kaufman Assessment Battery for Children," in Corsini Encyclopedia of Psychology, 2004.

[32] O. Goldhirsch, E. Wagner, and M. Vinokour, Mabatim: Looking on Children in Their Natural Environment, Ministry of Education Press, Tel-Aviv, Israel, 2002.

[33] A. Golos, M. Sarid, M. Weill, and N. Weintraub, "Efficacy of an early intervention program for at-risk preschool boys: a twogroup control study," American Journal of Occupational Therapy, vol. 65, pp. 400-408, 2011.

[34] G. Gioia, K. A. Espy, and P. K. Isquith, "Behavior Rating Inventory of Executive Function-Preschool Version (BRIEFP)," in Psychological Assessment Resources, Odessa, Fla, USA, 2003.

[35] G. A. Gioia, P. K. Isquith, P. D. Retzlaff, and K. A. Espy, "Confirmatory factor analysis of the Behavior Rating Inventory of Executive Function (BRIEF) in a clinical sample," Child Neuropsychology, vol. 8, no. 4, pp. 249-257, 2002.

[36] O. Bart, L. Rosenberg, N. Z. Ratzon, and T. Jarus, "Development and initial validation of the Performance Skills Questionnaire (PSQ)," Research in Developmental Disabilities, vol. 31, no. 1, pp. 46-56, 2010.

[37] N. Lifshitz and G. Tubul-Lavy, "Questionnaire for Assessing Preschoolers' Organizational Abilities (QAPOA)," in Proceedings of the The Annual Conference of Israeli Speech Therapists, Jerusalem, Israel, 2016.

[38] R. P. Bagozzi, Y. Yi, and L. W. Phillips, "Assessing construct validity in organizational research," Administrative Science Quarterly, vol. 36, no. 3, pp. 421-458, 1991. 
[39] E. DePoy and L. N. Gitlin, Introduction to Research, Elsevier, St. Louis, Mo, USA, 4th edition, 2011.

[40] N. O'Rourke, R. Psych, and L. Hatcher, A Step-by-Step Approach to Using SAS for Factor Analysis and Structural Equation Modeling, Sas Institute, Cary, NC, USA, 2013.

[41] American Occupational Therapy Association, "Occupational therapy practice framework: domain \& process," The American Journal of Occupational Therapy, vol. 68, pp. S1-S51, 2014.

[42] E. Schneider and S. Rosenblum, "Development, reliability, and validity of the my child's play (MCP) questionnaire," American Journal of Occupational Therapy, vol. 68, no. 3, pp. 277-285, 2014.

[43] K. D. Carlson and A. O. Herdman, "Understanding the impact of convergent validity on research results," Organizational Research Methods, vol. 15, no. 1, pp. 17-32, 2012. 


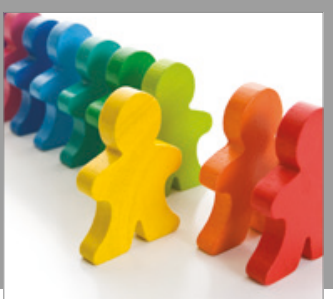

Autism

Research and Treatment
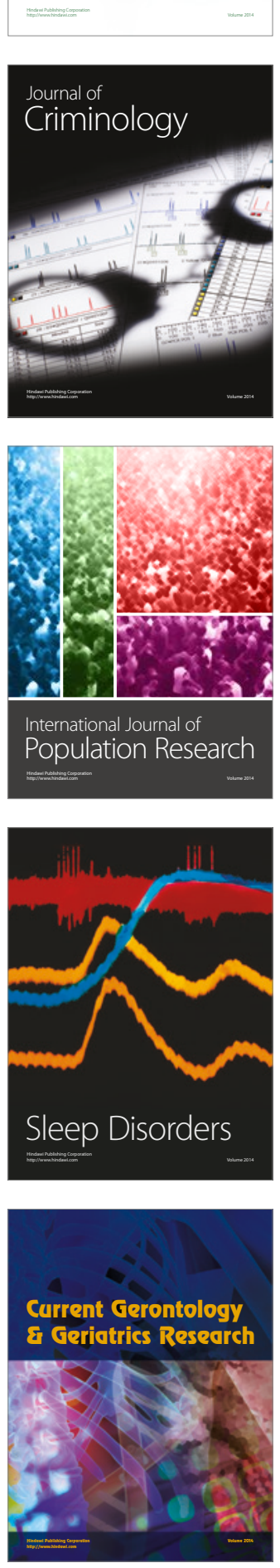

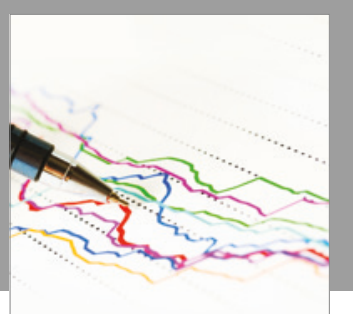

Economics

Research International

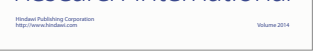

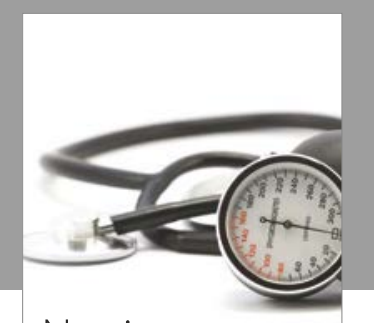

Nursing

Research and Practice



\section{Hindawi}

Submit your manuscripts at

https://www.hindawi.com
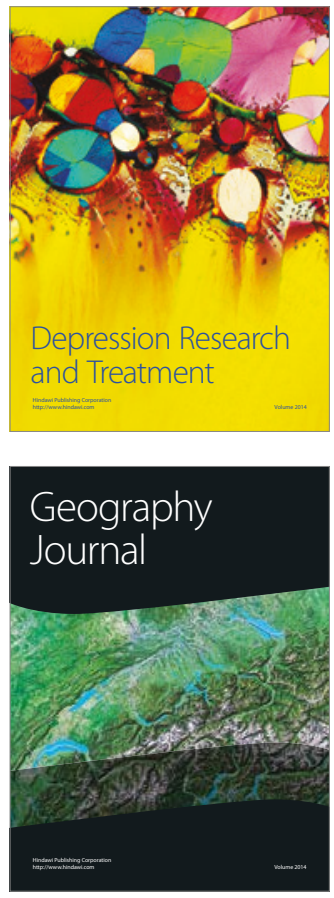
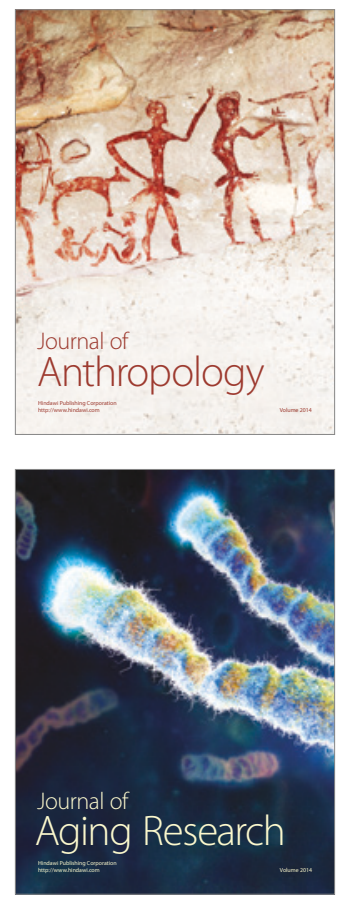
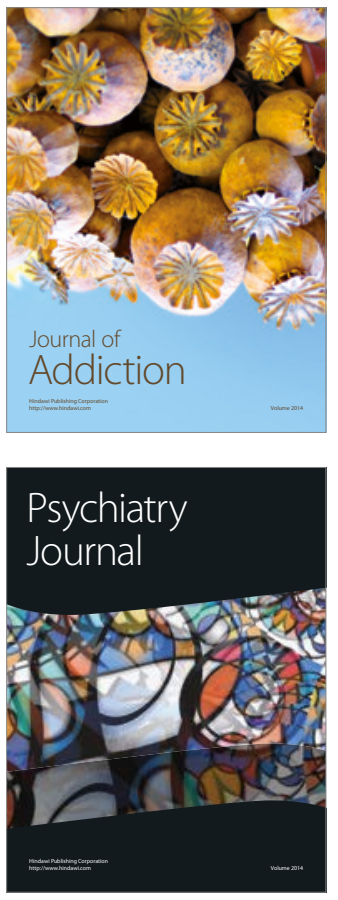

Child Development

Research

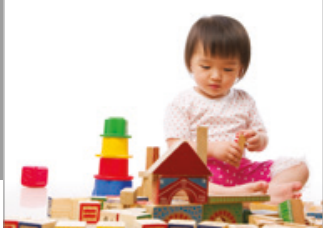

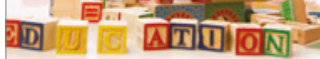
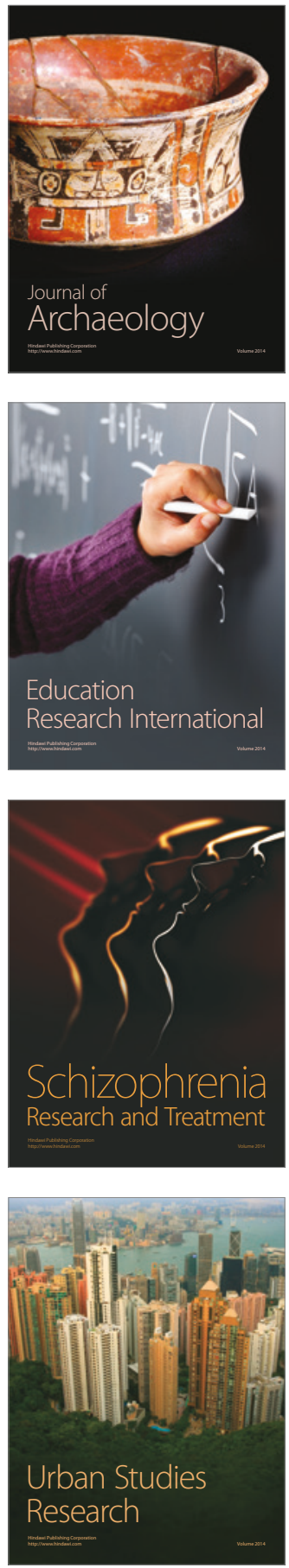